\title{
Medicinal Plant-based Functional Foods for the Management of Neurological Health
}

Md. Nasir Ahmed

Biotechnology \& Natural Medicine Division, TechB Nutrigenomics, Dhaka, Bangladesh Author (s) email id:

nasir.ahmedbd@hotmail.com ; nasir.ahmed@tech-b.org

Correspondence: Md. Nasir Ahmed, Biotechnologist

Mobile: +8801722599279;

No conflicts of interest to declare

Microsoft word count abstract: 191 


\title{
Medicinal Plant-based Functional Foods for the Management of Neurological Health
}

\begin{abstract}
Plants and plant-derived food products have been used for medicinal purposes since the ancient. Medicinal Plant-based functional foods or plant-based dietary compounds are a reemerged interest for their therapeutic benefits and nutritive supports which has implicated in healthcare systems across the world.

Neurological disorders are one of the greatest threats to public health and according to the World Health Organization, about 100 million people are affected globally by several neurological and mental ailments. In a traditional medication system, medicinal plants have been applied as both neuro-therapeutic purposes and micro-macro nutrients provider for the wellbeing of psychological states e.g. anti-depressant, anti-anxiety, anti-convulsions, anti-dementia, anti-psychotic, etc.

Herein, it is a topic of great interest to present a conceptual aspect by reviewing relevant scientific literature about the plant-based functional foods or bioactive phytochemicals for the prevention and treatment of mental and neurological disorders. From the literature assessment, we have found that nutritional neuroscience is becoming an advanced research discipline and there has been a growing pile of evidence concerning the therapeutic use of plant-based functional foods and/or plant-derived food compounds for the management of neurologic health, evolving with promising impact over the time.
\end{abstract}

Keywords: functional food, dietary supplement, phytochemicals, nutritional neuroscience, gut microbiome, personalized nutrition, Bangladesh 


\section{Introduction}

\section{"To eat is a necessity but to eat intelligently is an art" - La Rochefoucauld}

plants are the primary source of food for humankind. Consumption of food provides nutrition to the human body, improves their wellbeing, and on the other side foods can also be responsible for arising of ailments. The concept of "functional foods" is an emerging field in food science to reflect the philosophy- "food as medicine" beyond the basic nutrition needs [1]. The term "functional food" first came into sight in 1993 in the nature news magazine under the heading 'Japan explores the boundary between food and medicine' [2]. Bioactive compounds or functional components in food provide beneficial influences on body functions to help improving health and can be exerted in the treatment, reduction, and prevention of chronic diseases [3-4].

Functional foods and dietary supplements can be developed and produced by the addition of health-promoting bioactive components, reduction or elimination of harmful bioactive components, and even modification of the bioavailability of specific bioactive [5]. These active food/or bioactive components can derive both from phytochemicals (plant) and zoochemical (animal) and besides, the scientific evidence for functional foods and their bioactive components can be categorized into 4 following distinct areas [6]:

(1) clinical trials

(2) animal studies

(3) in-vitro laboratory studies, and

(4) epidemiologic studies.

The American Dietetic Association (ADA) classifies all foods as functional at some physiologic level and functional foods can be broadly grouped and categorized into the flowing table 1 \& table $2[\mathbf{1 , 7 ]} \&$ table 3 :

\begin{tabular}{|c|c|}
\hline Group & Examples \\
\hline Conventional food & $\begin{array}{c}\text {-glucan in oat bran to lower blood cholesterol } \\
\text { Fortified margarines that contains added } \\
\text { phytosterol and stanol esters that is known to } \\
\text { lower serum cholesterol }\end{array}$ \\
\hline Synthesized food & $\begin{array}{c}\text { some specialized carbohydrates intended to have } \\
\text { probiotic effects }\end{array}$ \\
\hline
\end{tabular}

Table 1: Groups of functional foods

\begin{tabular}{|c|c|}
\hline Category & Examples \\
\hline Basic Food & $\begin{array}{l}\text { Carrots (containing the anti-oxidant b- } \\
\text { carotene) }\end{array}$ \\
\hline Processed foods & Oat bran cereal \\
\hline Processed foods with added in & Calcium-enric \\
\hline $\begin{array}{l}\text { Food enhanced to have more of a functional } \\
\text { component }\end{array}$ & Tomatoes with a higher levels of lycopene \\
\hline $\begin{array}{l}\text { Isolated, purified preparations of active food } \\
\text { ingredients (dosage form) }\end{array}$ & $\begin{array}{l}\text { Isoflavones from soy; b-Glucan from oat } \\
\text { bran }\end{array}$ \\
\hline
\end{tabular}


Table 2: Categories of functional foods adapted from Arvanitoyannis and Van Houwelingen-Koukaliaroglou [7].

\begin{tabular}{|c|c|}
\hline Category & Selected examples \\
\hline $\begin{array}{c}\text { Conventional foods } \\
\text { (Whole foods) }\end{array}$ & Garlic Nuts Tomatoes \\
\hline Modified foods: & $\begin{array}{c}\text { Calcium-fortified orange juice, } \\
\text { Iodized salt }\end{array}$ \\
\hline Fortified & Folate-enriched breads \\
\hline Enriched & $\begin{array}{c}\text { Energy bars, snacks, yogurts, teas, bottled water, and } \\
\text { other functional foods formulated with bioactive } \\
\text { components such as lutein, fish oils, ginkgo biloba, St } \\
\text { John's wort, saw palmetto, and/or assorted amino } \\
\text { acids }\end{array}$ \\
\hline Enhanced & Phenylketonuria (PKU) formulas free of phenylalanine \\
\hline $\begin{array}{c}\text { Foods for special } \\
\text { dietary use }\end{array}$ & $\begin{array}{c}\text { Infant foods } \\
\text { Hypoallergenic foods such as gluten-free foods, } \\
\text { lactose-free foods, Weight-loss foods }\end{array}$ \\
\hline
\end{tabular}

Table 3: Categories of functional foods along with selected food examples adapted from Hasler and Brown [8].

\section{Ethnomedicinal Plant-based Functional Foods}

Plants have been utilized traditionally as therapeutic purposes or as food supplements in various cultures for centuries. Plants have a combination of secondary metabolites, also known as phytochemicals that are naturally occurred, gives therapeutic benefits with the supply of nutrition to the human body. Both medicinal plants and commonly consumed plants or plant products having the additional properties of promoting health or preventing diseases in addition to their property of supplying nutrients to the body can be considered as functional foods or nutraceuticals [9-10].

A vegetable can also contain different nutrients and phytochemicals [3], and numerous ethnomedicinal plants and their active phytochemical compounds have also been investigated for their role in disease prevention [6]. A study reported that leaves of Adenophora triphylla, a wild plant of Korea, is a potential source for functional foods that are commonly used for its analgesic, anti-inflammatory, and antitussive properties as well as a natural source of antioxidants [11]. A Cohort Study showed that consumption of onion (Allium серa) has an inverse relationship to the prevalence of stomach carcinoma [12]. In Bangladesh, some medicinal plants such as Aegle marmelos, Coccinia grandis, Hyptis suaveolens, Mangifera longipes, Nymphaea nouchali, Terminalia chebula, and Syzygium cumini used as food supplements by the Chakma tribe for treating several ailments like indigestion, piles, respiratory problems, diabetes, sex stimulant, cancer, liver diseases, hypertension, eyes diseases, tuberculosis, etc. [10]. Leaf juice of Mentha arvensis was used as a functional food by the Kavirajes of Dinajpur district, Bangladesh for dysentery, indigestion, and stomach pain [13]. In Chazuta valley (Peruvian Amazon), plants used 
traditionally in strict diets (where plant remedies are consumed with nearly fasting and with some sort of social seclusion), can contribute to the main effects through anti-inflammation, anti-infective actions, psycho-activity and depurative related activities [14]. The traditional Amazonian medicinal plants diet has globally become increasingly popular as complementary and alternative therapy practiced by shaman in Peru for the healing of various physical and mental conditions [15]. A systematic review [16] study reported that plants like Coccinia indica, Gymnema sylvestre, Aloe vera, and Momordica charantia, which are taken as food supplements show promise for glycemic control in diabetes. A study conducted in Turkey revealed that various Turkish herbs, that are used for edible purposes, contain bioactive principles for generating better human health and for the prevention of cancer [17].

Functional foods that are potentially beneficial in the prevention and treatment of cardiovascular disorders (CVD) include soybeans, oats, psyllium, flaxseed, garlic, tea, grapes and nuts [18], and the use of functional foods as potent drugs for the prevention of CVD due to inhibition of the inflammatory process, prevention of endothelial dysfunction, and vasodilator production [19].

The Allium genus, especially garlic (Allium sativum), onion (Allium cepa) and Chinese chive (Allium tuberosum) is rich in sulfur compounds, steroidal saponins, flavonoids, and so on, have anticancer, antioxidant, anti-platelet aggregation, anti-atherosclerosis, and antimicrobial activities [20] A study conducted in Taiwan, found good antioxidant and antimicrobial activity in several Zingiberaceae plants commonly known spices like ginger, turmeric [21]. Curcumin, a principal ingredient of turmeric (Curcuma longa) has antioxidant, anti-inflammatory, antiviral, and antifungal actions [22].

Beetroot (Beta vulgaris) has a long ethnopharmacological history in the treatment of tumors of the intestine, breast, stomach, and uterus [23] and consumption of beetroot leaf improves antioxidant capacity, reduces lipid peroxidation, and enhances glutathione levels [24].

\section{Medicinal Plant-based Foods and Phytochemicals for Neurologic Health}

Studies on the impact of plant-based functional foods or phytochemicals on brain function are still advancing. Effects of plant-based foods on brain health, cognitive functions, mental and neurological health as well as the underlying mechanisms remain largely unexplored [25]. Nevertheless, there has been a pile of reports in Bangladesh regarding the usage of medicinal plant-based functional foods as traditional phytotherapy for the maintenance of mental health $[\mathbf{9 , 1 0 , 1 3 ]}$. Ahmed and Azam [26] have evaluated 15 plant species that were reported to use by the traditional medicine practitioners of Bangladesh for the treatment of schizophrenia-like psychosis and accompanying symptoms like depression, insomnia, forgetfulness. In Ghana, thirty-two plant species have been identified to use as traditional medicine for treating mental and neurological disorders. Most of these plant species have reported anxiolytic, antidepressant, anticonvulsant, antipsychotic, sedative, anti-Alzheimer's, cognitive enhancement, motor coordination, and neuroprotective properties [27]. Plant-based traditional medicine is very common for treating neurological 
disorders in the West African region and sixty-seven plant species of Guinea Bissau flora were reported for the maintenance of several neurological and mental disorders e.g. epilepsy, convulsions, insanity, and depressant used by the traditional healers of West Africa [28].

Table 4: List of some medicinal plants which can be classified as functional foods, used by Bangladeshi traditional medicine practitioners for the management of neurologic and gut health $[9-10,13,92]$

\begin{tabular}{|c|c|c|}
\hline $\begin{array}{c}\text { Serial } \\
\text { Number }\end{array}$ & Plants name & Part(s) utilized \\
\hline 1 & Abroma augusta (L.) & roots \\
\hline 2 & Aegle marmelos (L.) & $\begin{array}{l}\text { Whole plant, leaf, } \\
\text { root, bark, fruit }\end{array}$ \\
\hline 3 & Amaranthus spinosus $\mathrm{L}$. & Leaf, stem \\
\hline 4 & Amaranthus viridis $\mathrm{L}$. & Leaf stem \\
\hline 5 & $\begin{array}{l}\text { Amomum subulatum } \\
\text { Roxb. }\end{array}$ & Seed \\
\hline 6 & $\begin{array}{l}\text { Asparagus racemosus } \\
\text { Wild. }\end{array}$ & Whole plant \\
\hline 7 & $\begin{array}{c}\text { Artocarpus } \\
\text { heterophyllus Lam. }\end{array}$ & Seed \\
\hline 8 & $\begin{array}{l}\text { Bacopa monnieri (L.) } \\
\text { Pennell }\end{array}$ & Leaf \\
\hline 9 & Bixa Orellana (L.) & Fruit \\
\hline 10 & Carissa carandas L. & Fruit \\
\hline 11 & Cayratia trifolia (L.) & Leaf \\
\hline 12 & Chenopodium album L. & Leaf, steam \\
\hline 13 & $\begin{array}{c}\text { Centella asiatica (L.) } \\
\text { Urb. }\end{array}$ & Leaf \\
\hline 14 & $\begin{array}{l}\text { Cinnamomum tamala } \\
\text { (Buch.-Ham.) T.Nees }\end{array}$ & Leaf \\
\hline 15 & $\begin{array}{c}\text { Cinnamomum } \\
\text { zeylanicum Blume }\end{array}$ & Bark \\
\hline 16 & Clitoria ternatea (L.) & Flower \\
\hline 17 & $\begin{array}{l}\text { Coccinia grandis (L.) J. } \\
\text { Voigt }\end{array}$ & $\begin{array}{l}\text { Whole plant, leaf, } \\
\text { stem, root, flower }\end{array}$ \\
\hline 18 & $\begin{array}{l}\text { Colocasia esculenta (L.) } \\
\text { Schott. }\end{array}$ & Leaf, stem, tuber \\
\hline 19 & Corchorus capsularis L. & Leaf \\
\hline 20 & Dillenia indica L. & Fruit \\
\hline 21 & $\begin{array}{l}\text { Glinus oppositifolius } \\
\text { (L.) Aug. DC. }\end{array}$ & Leaf \\
\hline 22 & Gmelina arborea Roxb. & Bark, fruit \\
\hline
\end{tabular}




\begin{tabular}{|c|c|c|}
\hline 23 & $\begin{array}{c}\text { Hyptis suaveolens (L.) } \\
\text { Poit. }\end{array}$ & $\begin{array}{c}\text { Whole plant, leaf, } \\
\text { bark, root, fruit, } \\
\text { seed }\end{array}$ \\
\hline 24 & Mentha arvensis L. & Leaf, stem \\
\hline 25 & Moringa oleifera Lam. & Leaf, fruit \\
\hline 26 & Musa x sapientum L. & Fruit \\
\hline 27 & $\begin{array}{c}\text { Nymphaea nouchali } \\
\text { Burm.f. }\end{array}$ & Leaf, stem \\
\hline 28 & Spilanthes acmella (L.) & Leaf \\
\hline 29 & $\begin{array}{c}\text { Syzygium aromaticum } \\
\text { (L.) Merr. }\end{array}$ & Flower bud \\
\hline 30 & $\begin{array}{c}\text { Syzygium cumini (L.) } \\
\text { Skeels }\end{array}$ & $\begin{array}{c}\text { Leaf, bark, fruit, } \\
\text { seed, seed kernel }\end{array}$ \\
\hline 31 & $\begin{array}{c}\text { Terminalia chebula } \\
\text { Retz. }\end{array}$ & $\begin{array}{c}\text { Leaf, bark, fruit, } \\
\text { seed }\end{array}$ \\
\hline 32 & Vitex negundo (L.) & Leaf \\
\hline
\end{tabular}

Foods containing phytochemicals like alkaloids, anthocyanins, carotenoids, and polyphenols, etc. are capable of improving cognitive function, learning, general brain, and wellbeing [29]. Zhang [30] identified extracts and constituents from 85 individual medicinal plants that have demonstrated potential efficacy for treating psychiatric disorders based on animal behavioral models. A bioactive component called Linalool, isolated from the leaf oil of Cinnamomum tamala has been reported to possess anti-inflammatory and antinociceptive properties including attenuation of allodynia in neuropathic pain induced by spinal nerve ligation in mice [31]. Phytochemicals like resveratrol, curcumin, and salvianolic acid derived from traditional Chinese herb Salvia miltiorrhiza, have reported protecting neurons in-vivo and in-vitro by activation of PI3K/Akt pathways [32]. Phytocompounds like Amentoflavone, bilobalide, hesperetin, luteolin, naringenin, quercetin, and resveratrol derived from the leaf of Ginkgo biloba has been reported to protect neurons from cell death and memory deficits via binding to the ATP-binding site on enzymes and receptors and via activating PI3K/Akt and PKC [33].

Aegle marmelos, commonly known as Bael, can be classified as a functional food and in India, it is a highly reputed Ayurvedic medicinal tree that has been used in nervous disorder and as a tonic for brain [34-35]. Methanolic extract of $A$. marmelos leaf possessed potential anxiolytic and antidepressant activities in albino mice and also may be served as a potential resource for natural psychotherapeutic agents [36]. The neuroprotective potential activity of ethanolic extract of $A$. marmelos leaf against streptozotocin-induced oxidative stress and cognitive deficit in rats indicated its therapeutic action in Alzheimer's diseases [37].

Peppers (Capsicum spp), is an important vegetable, widely consumed as a spice is rich in various phytochemicals like phenolics, alkaloids, and carotenoids, a natural pigment [3840]. Water extractable phytochemicals from Capsicum chinense and Capsicum annuum var. acuminatum inhibited acetylcholinesterase and butyrylcholinesterase 
activities and also exhibited antioxidant activities by scavenging free radicals and inhibiting pro-oxidant induced lipid peroxidation in rat brain homogenate in vitro [41].

Rosmarinic acid and its derivatives from Melissa officinalis plays a vital role for its antioxidant and neuroprotective actions and exhibited neurotrophic effect in the mechanisms that underlie memory-enhancing function by improving cholinergic activity [42] and the authors concluded that a variety of dietary phytochemicals that regulate neurodegenerative diseases by targeting neurotrophins might be a promising future [43].

Herbal coffees prepared from Phoenix dactylifera showed the highest enzyme inhibitory effects among the tested coffees obtained from Gundelia tournefortii, Nigella sativa, Phoenix dactylifera, and Ceratonia siliqua as well as a sample of instant coffee (Nescafe, green blend) [44]. The fruits of Pistacia terebinthus consumed in Turkey were explored for neuroprotective and antioxidant effects through enzyme inhibition tests against acetylcholinesterase, butyrylcholinesterase, and tyrosinase [45].

Rhizomes of Zingiber officinale, commonly known as ginger and used as a spice, reported having the ability to inhibit enzymes like acetylcholinesterase and butyrylcholinesterase that linked to neurodegenerative diseases [46]. It is also demonstrated [47] that ginger reverses behavioral dysfunction and prevents Alzheimer's like symptoms in the rat model. Sharma et al., [48] suggested that neuroprotective actions of zinger roots are mediated via its anticholinesterase activity and the experiment has been done for the treatment of Huntington's disease. The extract restored behavioral and biochemical changes induced by a neurotoxin, 3-nitropropionic acid.

An edible plant Morinda citrifolia, known as Noni, popularly used as food [49]. The antipsychotic-like activity of $M$. citrifolia in mice demonstrated the anti-dopaminergic effect, suggested that this plant has an antipsychotic-like activity that can be utilized in the treatment of psychiatric disorders [50]. Another finding [51] suggested that Noni exhibits more obvious inhibitory effects on hydrocephalus-induced neurodegenerative disorder than memantine (has been used for the treatment of Alzheimer's disease) in periventricular tissue of the fourth ventricle. The neuroprotective effect of the Noni extract might occur partly via the improvement of oxidative stress status in the cortex [52].

Silva and Pogacnik [53] stated that polyphenols are promising molecules for the prevention and treatment of neurodegenerative diseases and antioxidant-based mechanisms of polyphenols can modulate several cell-signaling pathways and mediators. Plant-derived polyphenols such as curcumin, resveratrol, propolis, ginsenoside, rosmarinic acid, and polyunsaturated fatty acids have been applied to numerous neurodegenerative diseases for their anti-oxidative and anti-inflammatory effects that have been widely confirmed invivo and in-vitro [54]. Flavonoids belonging to the group of polyphenols, which are rich in vegetables, fruits, grains, and teas, have been investigated about their ability to prevent or reverse cognitive related deficits by numerous mechanism [55-56]. 
Resveratrol has been reported to have powerful neuroprotective effects by several different studies and confirmed in neurodegenerative disorders like traumatic brain injury [5758] and Alzheimer's disease, Parkinson's disease [59]. Supplementation of resveratrol might enhance memory performance in older people, potential mechanisms have been addressing underlying this effect [60]. Kennedy et al., [61] suggested that a single dose of orally administered resveratrol can modulate cerebral blood flow variables.

\section{Discussions}

In sum, the therapeutic effects of whole foods and plants as neuroprotective agents are becoming the attention of research by neuroscientists [62-63]. Kennedy and Wightman [64] in his review, have assessed the available evidence for the efficacy of plantbased extracts and phytochemicals that may improve brain function and also reach a conclusion to their potential effectiveness as nootropics. A review done by Naoi et al. [65] has studied multiple neuroprotective activities of phytochemicals via targeting oxidative stress, neuroinflammation, mitochondrial dysfunction, neurotrophic factor deficit, apoptosis, and accumulation of abnormal-modified protein. The authors in another study [66] also proposed phytobioactive polyphenols as one of the most promising mitochondria-targeting medicine to preserve the activity, structure of mitochondria, and neurons. Data accumulation [67] suggested that phytochemicals from fruits, vegetables, herbs, and spices may exert relevant immunomodulatory and anti-inflammatory activities in the context of brain aging and randomized controlled trials should be performed in humans to invent the real impact of dietary phytochemicals which can play a pivotal role in the prevention and treatment of neuro-inflammaging [68].

\subsection{Microbes, brain and food}

The human intestinal microbiota (gut microbiome) has an important role in shaping brain functions and behavior [69], and changes of the gut microbiome in people experiencing psychological illness such as schizophrenia and depression, as well as neurological disorders such as Parkinson's disease [70], and recent research has been reported on the role of gut microbiota in the development of autism spectrum disorders [71]. Because of the food we eat can also influence the structure and activity of the gut microbiota [72]. Different gut microbiota thrives on different foods to play multiple important roles in human physiology via extracting nutrients and energy from ingested foods and contributes to the immune function of the host [73-74]. Dietary polyphenols have an important impact on brain modulation [75] and the biotransformation of polyphenols is needed to obtain metabolites (the small byproducts of microbial digestion, those can send signals to the brain) active in brain processed by the gut microbiota [76].

\subsection{Interaction between gut microbiome and medicinal plants}

An et al., [77] has found two pathways while investigating the interaction between the gut microbiota and herbal medicines. One is the digestion of herbal medicines into absorbable active small molecules that enter the body to induce physiological changes and another pathway is the change of gut microbiota composition and its secretion by herbal medicines which induce pharmacological effects. Another review [78] study has summarized the interactions between gut microbiota and ethnomedicine constituents via highlighting the modulation of the gut microbiota profile by ingested natural compounds and the gut 
microbial conversion of natural products into the "daughter molecules" with potent bioactivities. Recent studies [79-80] are also suggesting that certain foods or the Mediterranean diet are associated with friendly gut microbiota that aids the biosynthesis of essential nutrients and the production of short-chain fatty acids. The influx of review studies indicates that the role and utilization of gut microbiome as therapeutic purposes and their correlations with the diet components in the management of neurologic disorders has become a fascination over the time for the research [81-91].

To be concluded, it is essential to emphasize on doing more research to outshine the insights of the role of medicinal plant-based foods and/or plant-derived bioactive components to the gut microbiota and their interaction mechanisms that impact on the brain function and to also elucidate the nutrition-gene interactions that exert neurological benefits, to optimize cognitive function and promote the plant-based personalized nutritional diets or personalized nutrition practices in the management of multiple devastating neurologic disorders that lead to mental wellness as well.

\section{References:}

1. Henry, CJ., "Functional foods". European Journal of Clinical Nutrition 64 (2010): 657659; doi:10.1038/ejcn.2010.101

2. Swinbanks, D., et al. "Japan explores the boundary between food and medicine". Nature 364 (1993): 180.

3. Hasler, CM. "Functional foods: benefits, concerns and challenges-a position paper from the american council on science and health". The Journal of Nutrition 132.12 (2002): 3772-81. doi: 10.1093/jn/132.12.3772

4. Abuajah, CI., et al. "Functional components and medicinal properties of food: a review". Journal of Food Science and Technology 52.5 (2015): 2522-9. doi:10.1007/s13197-014-1396-5.

5. Abdel-Salam, AM., "Functional Foods: Hopefulness to Good health". American Journal of Food Technology, 5.2 (2010): 86-99. DOI: 10.3923/ajft.2010.86.99

6. Hasler, CM., et al. "Position of the American Dietetic Association: Functional foods". Journal of the American Dietetic Association 104.5 (2004): 814-26. doi: 10.1016/j.jada.2004.03.015

7. Arvanitoyannis, IS., et al. "Functional foods: a survey of health claims, pros and cons, and current legislation". Critical Reviews in Food Science and Nutrition 45.5 (2005): 385-404.

8. Hasler, CM., et al. 'American Dietetic Association (2009). Position of the American Dietetic Association: functional foods". Journal of the American Dietetic Association 109.4 (2009): 735-46.

9. Rahmatullah, M., et al. "A survey of medicinal and functional food plants used by the folk medicinal practitioners of three villages in Sreepur Upazilla, Magura district, Bangladesh". American-Eurasian Journal of Sustainable Agriculture, 4.3 (2010): 363373.

10. Rahmatullah M., et al. "An Ethnomedicinal Survey of Medicinal Plants Used as Food Supplements by the Chakma Tribe of Bandarban District, Bangladesh". Journal of Phytomedicine and Therapeutics, 14 (2009): 7-16. 
11. Kim, JH., et al. "Comparison of antioxidant activity in wild plant (Adenophora triphylla) leaves and roots as a potential source of functional foods". International Journal of Food Sciences and Nutrition 60.Suppl2 (2009): 150-161.

12. Dorant, E., et al. "Consumption of onions and a reduced risk of stomach carcinoma". Gastroenterology, 110.1 (1996): 12-20.

13. Rahmatullah, M., et al. "A survey of medicinal plants in two areas of Dinajpur district, Bangladesh including plants which can be used as functional foods". AmericanEurasian Journal of Sustainable Agriculture, 3.4 (2009): 862-876.

14. Sanz-Biset, J and Cañigueral, S. "Plant use in the medicinal practices known as "strict diets" in Chazuta valley (Peruvian Amazon)". Journal of Ethnopharmacology, 137.1 (2011): 271-88. doi: 10.1016/j.jep.2011.05.021.

15. Politi, M., et al. "Medicinal Plants Diet as Emerging Complementary Therapy from the Amazonian Tradition. Data from Centro Takiwasi, a Peruvian Therapeutic Community." Journal of Medicinal Herbs and Ethnomedicine, 5 (2019): 23-28, doi:https://doi.org/10.25081/jmhe.2019.v5.5692.

16. Yeh, GY., et al. "Systematic review of herbs and dietary supplements for glycemic control in diabetes". Diabetes Care, 26.4 (2003): 1277-1294.

17. Esiyok, D., et al. "Herbs as a food source in Turkey". Asian Pacific Journal of Cancer Prevention. $5.3: 334-339$.

18. Hasler, CM., et al. "Functional foods and cardiovascular disease". Current Atherosclerosis Reports, 2: (200): 467-475.

19. Asgary, S., "Functional Food and Cardiovascular Disease Prevention and Treatment: A Review". Journal of the American College of Nutrition 37.5 (20000: 429-455. doi: 10.1080/07315724.2017.1410867

20. Yoshimoto, N., et al. Identification of a Flavin containing S-oxygenating monooxygenase involved in alliin biosynthesis in garlic. The Plant Journal. 83.6 (2015): 941-51. doi:10.1111/tpj.12954.

21. Chen, IN., et al. "Antioxidant and antimicrobial activity of Zingiberaceae plants in Taiwan". Plant Foods for Human Nutrition, 63.1 (2008): 15-20.

22. Akram, M., et al. "Curcuma longa and curcumin: a review article". Romanian Journal of Biology - Plant Biology 55.2 (2010): 65-70.

23. Jain, NK., et al. "Protective role of Beta vulgaris L. leaves extract and fractions on ethanol-mediated hepatic toxicity". Acta Poloniae Pharmaceutica 69.5 (2012): 94550.

24. Sener, G., et al. "Effects of chard (Beta vulgaris L. var. cicla) extract on oxidative injury in the aorta and heart of streptozotocin-diabetic rats". Journal of medicinal food 5.1 (2002): 37-42. doi:10.1089/109662002753723205.

25. Medawar, E., et al. "The effects of plant-based diets on the body and the brain: a systematic review". Translational Psychiatry. 9.1 (2019): 226. doi: 10.1038/s41398019-0552-0.

26. Ahmed, MN and Azam, MNK., "Traditional knowledge and formulations of medicinal plants used by the traditional medical practitioners of Bangladesh to treat schizophrenia like psychosis'. Schizophrenia Research Treatment. 2014 (2014): 679810. doi: 10.1155/2014/679810 
27. Amoateng P., et al. "Medicinal Plants Used in the Treatment of Mental and Neurological Disorders in Ghana". Evidence Based Complementary and Alternative Medicine 2018 (2018): 8590381. doi: 10.1155/2018/8590381

28. Romeiras M., et al. "Medicinal Plants Used to Treat Neurological Disorders in West Africa: A Case Study with Guinea-Bissau Flora". American Journal of Plant Sciences, 3.7 (2012): 1028-1036. doi: 10.4236/ajps.2012.327122.

29. Olasehinde, TA., et al. "Functional foods in the management of neurodegenerative diseases". (2017) In book: Functional Foods: UNLOCKING THE MEDICINE IN FOODS Edition: 1 Chapter: 6 Publisher: Graceland Prints, Editors: Prof Ganiyu Oboh

30. Zhang, Z., "Therapeutic effects of herbal extracts and constituents in animal models of psychiatric disorders”, Life Sciences, 75.14 (2004): 1659-1699.

31. Berliocchi, R., et al. "(-)-Linalool attenuates allodynia in neuropathic pain induced by spinal nerve ligation in c57/b16 mice". International Review of Neurobiology, 85 (2009): 221-235.

32. Vauzour, D., et al., "Activation of pro-survival Akt and ERK1/2 signalling pathways underlie the anti-apoptotic effects of flavonones in cortical neurons". Journal of Neurochemistry 103.4 (2007): 1355-1367.

33. Hwang, SL., and Yen, GC., "Modulation of Akt, JNK, and p38 activation is involved in citrus flavonoid-mediated cytoprotection of PC12 cells". Journal of Agriculture and Food chemistry 57.6 (2009): 2576-2582.

34. Raj KPS and Patel MR., "Some medicinal plants of Cambay and its immediate vicinity and their uses in Indian indigenous system of medicine". Indian Drugs, 15: (1978): 145-152.

35. Maheshwari JK and Singh JP., "Plants used in ethnomedicine by the Kols of Allahabad district Uttar Pradesh". Bulletin of Medico-Ethno-Botanical Research 5: (1984): 105121.

36. Kothari S., Et al. "Anxiolytic and antidepressant activities of methanol extract of Aegle marmelos leaves in mice". Indian Journal of Physiology and Pharmacology, 54.4 (2010): 318-328.

37. Raheja S, et al., 'Aegle marmelos leaf extract ameliorates the cognitive impairment and oxidative stress induced by intracerebroventricular streptozotocin in male rats". Life Sciences 221 (2019): 196-203. doi: 10.1016/j.lfs.2019.02.032.

38. Materska M., et al. "Antioxidant activity of the main phenolic compounds isolated from hot pepper fruits (Capsicum annuum L.)". Journal of Agriculture and Food Chemistry 53 (2005): 1730 - 1758

39. Guil-Guerrero JL., et al. "Nutrient Composition and Antioxidant Activity of 10 pepper (Capsicum annuum) varieties". European Food Research and Technology 224 (2006): 1-9.

40. Conforti, F., et al. "Chemical and biological variability of hot pepper fruits (Capsicum annuum var. acuminatum L.) in relation to maturity stage". Food Chemistry, 102 (2007): 1096-1104.

41. Ogunruku, 00., et al. "Capsicum annuum var. grossum (Bell Pepper) Inhibits âSecretase Activity and â-Amyloid1-40 Aggregation". Journal of Medicinal Food 20 (2017): 124-130. 
42. Omri, AE., et al. Rosmarinus officinalis polyphenols activate cholinergic activities in PC12 cells through phosphorylation of ERK1/2, Journal of Ethnopharmacology, 131.2 (2010): 451- 458.

43. Venkatesan R., et al. "Phytochemicals That Regulate Neurodegenerative Disease by Targeting Neurotrophins: A Comprehensive Review". Biomed Research International 2015 (2015): 814068.

44. Sekeroglu, N., et al. "In vitro prospective effects of various traditional herbal coffees consumed in Anatolia linked to neurodegeneration". Food Research International 45.1 (2012): 197-203.

45. Orhan, IE., et al. "Neuroprotective potential of some terebinth coffee brands and the unprocessed fruits of Pistacia terebinthus L. and their fatty and essential oil analyses". Food Chemistry 130.4 (2012): 882-888.

46. Oboh G, et al. "Inhibition of acetylcholinesterase activities and some pro-oxidant induced lipid peroxidation in rat brain by two varieties of ginger (Zingiber officinale)". Experimental and Toxicologic Pathology 64 (2012): 315-319.

47. Zeng GF., et al. "Protective effects of ginger root extract on Alzheimer disease-induced behavioral dysfunction in rats". Rejuvenation Research 16.2 (2013): 124-133.

48. Sharma M, et al., "Neuroprotective effect of Zingiber officinale in 3-np-induced Huntington disease'. IOSR Journal of Pharmacy 2.6 (2012): 61-70.

49. Mandukhail SU., et al. "Studies on antidyslipidemic effects of Morinda citrifolia (Noni) fruit, leaves and root extracts'. Lipids in Health and Disease, 9.1 (2010): 88.

50. Vijayapandi P., et al. "Antipsychotic-like activity of noni (Morinda citrifolia Linn.) in mice'. BMC Complementary and Alternative Medicine, 12 (2012): 186.

51. Köktürk S., et al. "Morinda citrifolia L. (noni) and memantine attenuate periventricular tissue injury of the fourth ventricle in hydrocephalic rabbits". Neural Regeneration Research 8.9 (2013): 773-82.

52. Wattanathorn J., et al. "Morinda citrifolia L. Leaf Extract Protects against Cerebral Ischemia and Osteoporosis in an In Vivo Experimental Model of Menopause". Oxidative Medicine and Cellular Longevity. 2018 (2018): 1039364.

53. Silva RFM and Pogacnik L. "Polyphenols from food and natural products; Neuroprotection and safety". Antioxidants, 9.1 (2020): 61.

54. Wang J., et al. "Neuroprotective Effect of Several Phytochemicals and Its Potential Application in the Prevention of Neurodegenerative Diseases". Geriatrics (Basel). 1.4 (2016): pii: E29.

55. Panickar, KS, Jang S. "Dietary and plant polyphenols exert neuroprotective effects and improve cognitive function in cerebral ischemia". Recent Patents on Food, Nutrition and Agriculture 5.2 (2013): 128-143.

56. Spencer SJ., et al. "Food for thought: how nutrition impacts cognition and emotion", npj Science of Food 1, 7 (2017).

57. Ates, 0., et al. "Neuroprotection by resveratrol against traumatic brain injury in rats". Molecular and cellular biochemistry 294.1-2 (2007): 137-144.

58. Zhang, Q., et al. "Resveratrol attenuates hypoxia-induced neurotoxicity through inhibiting microglial activation". International Immunopharmacology. 28 (2015): 578-587. 
59. Albani, D., et al. "The SIRT1 activator resveratrol protects SK-N-BE cells from oxidative stress and against toxicity caused by alpha-synuclein or amyloid-beta (142) peptide". Journal of Neurochemistry. 110 (2009): 1445-1456.

60. Witte, AV., et al. "Effects of resveratrol on memory performance, hippocampal functional connectivity, and glucose metabolism in healthy older adults". Journal of Neuroscience. 34 (2014): 7862-7870.

61. Kennedy, DO., et al. "Haskell CF. Effects of resveratrol on cerebral blood flow variables and cognitive performance in humans: a double-blind, placebo-controlled, crossover investigation". American Journal of Clinical Nutrition 91 (2010): 1590-1597.

62. Davinelli, S., et al. "Epigenetic nutraceutical diets in Alzheimer's disease". Journal of Nutrition, Health \& Aging 18.9 (2014): 800-805.

63. Aiello A., et al. "Nutrigerontology: A key for achieving successful ageing and longevity". Immunity \& Ageing 13 (2016): 17.

64. Kennedy DO, Wightman EL. "Herbal extracts and phytochemicals: plant secondary metabolites and the enhancement of human brain function". Advances in Nutrition 2.1 (2011): 32-50.

65. Naoi, M., $\mathrm{t}$ al. Neuroprotection of multifunctional phytochemicals as novel therapeutic strategy for neurodegenerative disorders: Antiapoptotic and antiamyloidogenic activities by modulation of cellular signal pathways. Future Neurol. 14 (2019): FNL9.

66. Naoi, M., et al. "Mitochondria in Neuroprotection by Phytochemicals: Bioactive Polyphenols Modulate Mitochondrial Apoptosis System, Function and Structure. International Journal of Molecular sciences 20.10 (2019): 2451.

67. Corbi G., et al. "Dietary Phytochemicals in Neuroimmunoaging: A New Therapeutic Possibility for Humans?" Frontiers in Pharmacology 7 (2016): 364.

68. Davinelli S., et al. "Dietary phytochemicals and neuro-inflammaging: from mechanistic insights to translational challenges". Immunity \& Ageing. 13 (2016): 16.

69. Vagnerová K., et al., "Interactions Between Gut Microbiota and Acute Restraint Stress in Peripheral Structures of the Hypothalamic-Pituitary-Adrenal Axis and the Intestine of Male Mice". Frontiers in Immunology. 10 (2019): 2655.

70. Dinan TG and Cryan JF. "The impact of gut microbiota on brain and behaviour: implications for psychiatry". Current Opinion in Clinical Nutrition \& Metabolic Care. 18.6 (2015): 552-8.

71. Kantarcioglu, AS., et al. "Microbiota-Gut-Brain Axis: Yeast Species Isolated from Stool Samples of Children with Suspected or Diagnosed Autism Spectrum Disorders and In Vitro Susceptibility Against Nystatin and Fluconazole". Mycopathologia 181 (2016): 1-7.

72. David LA., et al. "Diet rapidly and reproducibly alters the human gut microbiome". Nature. 505.7484 (2014): 559-63.

73. Sankar SA et al. "The human gut microbiome, a taxonomic conundrum". Systematic and Applied Microbiology 38.4 (2014): 276-86.

74. Santoro A, et al. "Gut microbiota changes in the extreme decades of human life: a focus on centenarians". Cellular and Molecular Life Sciences 75.1 (2018): 129-148.

75. Szwajgier D, et al. "The Neuroprotective Effects of Phenolic Acids: Molecular Mechanism of Action". Nutrients 9.5 (2017): pii: E477.

76. Filosa S, et al. "Polyphenols-gut microbiota interplay and brain neuromodulation". Neural Regeneration Research 13.12 (2018): 2055-2059. 
77. An X, et al. "The interaction between the gut Microbiota and herbal medicines". Biomed and Pharmacotherapy 118 (2019): 109252. doi: 10.1016/j.biopha.2019.109252.

78. Wu XM and Tan RX. "Interaction between gut microbiota and ethnomedicine constituents". Natural Product Reports 36.5 (2019): 788-809

79. Valdes AM, et al. "Role of the gut microbiota in nutrition and health". BMJ 361 (2018): $\mathrm{k} 2179$.

80. Rinninella E, et al. "Food Components and Dietary Habits: Keys for a Healthy Gut Microbiota Composition". Nutrients 11.10 (2019): pii: E2393. doi: 10.3390/nu11102393.

81. Pistollato F, et al. "Role of gut microbiota and nutrients in amyloid formation and pathogenesis of Alzheimer disease". Nutrition Reviews 74.10 (2016): 624-34.

82. Lombardi VC, et al. "Nutritional modulation of the intestinal microbiota; future opportunities for the prevention and treatment of neuroimmune and neuroinflammatory disease". Journal of Nutritional Biochemistry. 61 (2018): 1-16.

83. Tengeler AC., et al. "Relationship between diet, the gut microbiota, and brain function". Nutrition Reviews. 76.8 (2018): 603-617. doi: 10.1093/nutrit/nuy016.

84. Westfall S, Pasinetti GM. "The Gut Microbiota Links Dietary Polyphenols with Management of Psychiatric Mood Disorders". Frontiers in Neuroscience 13 (2019): 1196.

85. Ma Q, Xing C, et al. "Impact of microbiota on central nervous system and neurological diseases: the gut-brain axis". Journal of Neuroinflammation. 16.1 (2019):53. doi: 10.1186/s12974-019-1434-3.

86. Larroya-García A, et al. "Impact of gut microbiota on neurological diseases: Diet composition and novel treatments". Critical Reviews in Food Science \& Nutrition 59.19 (2019): 3102-3116. doi: 10.1080/10408398.2018.1484340.

87. Grochowska M., et al. "Gut microbiota in Neurological disorders". Archivum Immunologiae et Therapiae Experimentalis 67 (2019): 375-383

88. Cryan JF., "The gut microbiome in neurological disorders". The Lancet Neurology 19.2 (2020): 179-194. doi: 10.1016/S1474-4422(19)30356-4.

89. Parker A, et al. "Gut microbes and metabolites as modulators of blood-brain barrier integrity and brain health". Gut Microbes. 11.2 (2020): 135-157. doi: 10.1080/19490976.2019.1638722.

90. Vamanu E, Gatea F. "Correlations between Microbiota Bioactivity and Bioavailability of Functional Compounds: A Mini-Review'. Biomedicines 8.2 (2020): pii: E39. doi: 10.3390/biomedicines8020039.

91. Zhu S, et al. "The progress of gut microbiome research related to brain disorders". Journal of Neuroinflammation 17.1 (2020):25. doi: 10.1186/s12974-020-1705-z.

92. Azam FM, et al., "Are famine food plants also ethnomedicinal plants? An ethnomedicinal appraisal of famine food plants of two districts of Bangladesh". Evidence Based Complementary and Alternative Medicine 2014 (2014): 741712. 